\title{
Doctor-diagnosed health problems in a region with a high density of concentrated animal feeding operations: a cross-sectional study
}

Mariëtte Hooiveld ${ }^{1 *}$, Lidwien A. M. Smit ${ }^{2}$, Femke van der Sman-de Beer ${ }^{1}$, Inge M. Wouters², Christel E. van Dijk ${ }^{1}$, Peter Spreeuwenberg ${ }^{1}$, Dick J. J. Heederik ${ }^{2}$ and C. Joris Yzermans ${ }^{1}$

\begin{abstract}
Background: There is growing interest in health risks of residents living near concentrated animal feeding operations (CAFOs). Previous research mostly focused on swine CAFOs and self-reported respiratory conditions. The aim was to study the association between the presence of swine, poultry, cattle and goat CAFOs and health of Dutch neighbouring residents using electronic medical records from general practitioners (GPs).

Methods: Data for the year 2009 were collected of 119,036 inhabitants of a rural region with a high density of CAFOs using information from GIAB (high exposed population). A comparison was made with GP data from 78,060 inhabitants of rural areas with low densities of CAFOs (low exposed population). Associations between the number of CAFOs near residents' homes and morbidity were determined by multilevel (cross-classified) logistic regression.

Results: In 2009, the prevalence of most respiratory and gastrointestinal conditions was similar in the high and low exposed population. Exceptions were pneumonia, atopic eczema and unspecified infectious diseases with an increased prevalence, and sinusitis with a decreased prevalence in the high exposed population. Within the high CAFO density region, the number of poultry, cattle and swine CAFOs near residents' homes was not associated with allergic, respiratory or gastrointestinal conditions. Conversely, each additional goat CAFO within the postal code area of residents' homes significantly increased the odds of unspecified infectious disease and pneumonia by 87 and 41 percent, respectively.

Conclusions: Using GP records, pneumonia and unspecified infectious diseases were positively associated with the number of goat CAFOs near residents' homes, but no association was found between swine, cattle, and poultry CAFOs and respiratory, allergic or gastrointestinal conditions.
\end{abstract}

Keywords: Livestock, Poultry, Public health, Environmental exposure, Multilevel analysis

\section{Background}

There is growing attention for health problems of residents living in the proximity of livestock farms. Radon et al. suggested that a high density of animal houses in the proximity of neighbouring residents adversely affects respiratory health [1]. In 2010, a systematic review described the association between livestock farms and measures of respiratory, gastrointestinal (GI) and mental

\footnotetext{
* Correspondence: m.hooiveld@nivel.nl

${ }^{1} \mathrm{NIVEL}$, Netherlands institute for health services research, P.O. Box

15683500BN Utrecht, The Netherlands

Full list of author information is available at the end of the article
}

health of individuals living near these facilities [2]. The authors concluded that there was little compelling evidence for a consistent strong association between proximity to animal farms and clinical measures of disease. More recent studies among neighbouring residents showed either no, or inverse, associations with respiratory health and allergies or positive associations with physical symptoms [3-7].

Although several studies have addressed the possible adverse health effects of animal farm emissions among neighbouring residents, there are still issues that need further investigation. First, in several studies it was 
unclear whether the research involved animal farms in general or more specifically concentrated animal feeding operations (CAFOs), because detailed information about the livestock population size was lacking [2]. Second, most research has been performed on swine CAFOs specifically. Third, most published studies are based on patient-reported symptoms, while it is known that prevalence estimates derived from self-reported data deviate from those obtained from general practitioners' (GPs) medical records [8]. Finally, most studies focussed on respiratory health and allergies, but only a few addressed the possible relation between CAFOs and GI outcomes $[9,10]$.

In the Netherlands, the number of CAFOs (also called mega-farms) has doubled between the years 2000 and 2009 [11]. In contrast to other countries, in the Netherlands a high animal density is paralleled by a high human population density, resulting in a large human population potentially at risk of adverse health effects. After an outbreak of swine fever in the Netherlands in 1997, the government decided to allocate specific areas for intensive livestock farming. The eastern part of the province Noord-Brabant and the northern part of the adjacent province of Limburg, also known as 'the Peel', is a region with mainly poor, sandy soils, and a history of livestock farming. Within this Peel region, many areas were allocated for intensive livestock farming. After the Q fever epidemic in 2009, there were growing concerns about adverse health effects of living near CAFOs in general, especially in this Peel region. In response to this, the Dutch government decided to fund the described study on the health of residents. We carried out a study evaluating health problems of more than 100,000 individuals living in this rural region with a high density of farm animals, using data obtained from electronic medical records (EMRs) registered by Dutch GPs [12]. Previously, we reported the results of associations between the presence and numbers of farm animals within $5 \mathrm{~km}$ of the home address and GP-registered health problems $[5,13]$. However, reports about $Q$ fever outbreaks suggested windborne spread of Coxiella burnetii aerosols over several kilometres [14]. In addition, airborne cow allergens have been found at distances up to $4.8 \mathrm{~km}$ of dairy facilities [15]. On the other hand, for a given number of animals in the home environment, potential health effect might be different with many small-scale farms compared to one large farm. Therefore, the aim of the current study was to evaluate associations of swine, poultry, cattle and goat CAFOs with health problems among neighbouring residents using a semi-individual design. We first compared the prevalence of GPregistered health problems of residents living in the rural region with a high CAFO density to those living in rural regions with a low CAFO density. Next, within the high
CAFO density region, we evaluated health effects with the number of CAFOs located in the proximity of residents' homes.

\section{Methods}

\section{Study population}

All Dutch citizens are obligatory registered with a general practice in the proximity of their home (usually $10 \mathrm{~km}$ ) and GPs have a gatekeeper role for access to specialized, secondary care. Therefore, records kept by GPs provide a good and complete picture of people's health, while the number of enlisted patients can be used a the denominator in epidemiological studies. The guidelines of the Dutch College of General Practitioners require that GPs record morbidity data of their patients in EMRs using the International Classification of Primary Care (ICPC) $[16,17]$.

The study region was chosen, as it is the part of the Netherlands with the highest density of CAFOs. No other regions in the Netherlands have this many CAFOs. The region covered the eastern part of the province Noord-Brabant, excluding the urban areas, and the north-western part of the province Limburg (Fig. 1). These two provinces, out of a total of twelve, have 208 (48 \%) of all CAFOs in the Netherlands [11]. Between December 2009 and March 2010, general practices

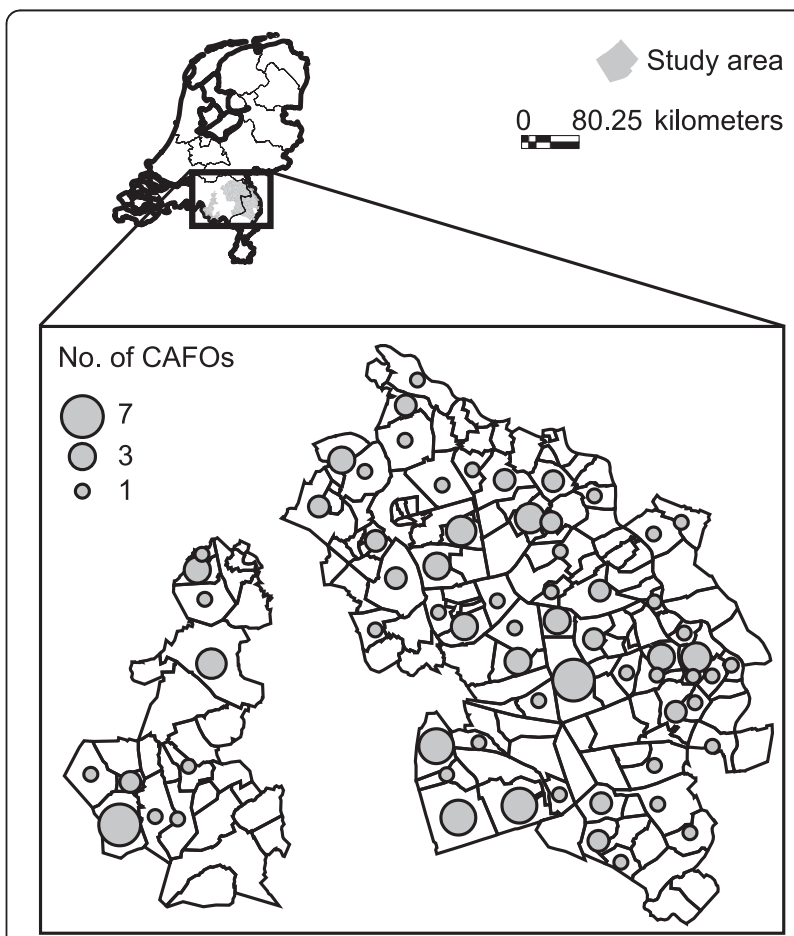

Fig. 1 High CAFO density study region: eastern part of province of Noord-Brabant and northern part of province of Limburg. For each postal code area the number of CAFOs is indicated (GIAB 2009, Alterra Wageningen UR, the Netherlands) 
located in rural postal code areas $(<1500$ addresses per $\mathrm{km}^{2}$ according to National Statistics) in this region with high CAFO density were asked to participate through regional professional newsletters. Forty-nine practices applied, whereof 28 (57 \%) practices that met predefined registration quality criteria were included in the study [13]. Fourteen practices included were participants of NIVEL Primary Care Database, formerly known as Netherlands Information Network of General Practice (LINH) [18]. EMR data of the year 2009 was available for 119,036 enlisted persons (19 \% of the total population in this region), including those who did not consult their GP. We refer to this population as the high exposed group.

A comparison was made with patients of general practices of NIVEL Primary Care Database located in other rural postal code areas throughout the Netherlands. Using the same quality criteria, we included 78,060 enlisted patients of 22 eligible general practices. We refer to this population as low exposed to CAFO.

The study was carried out according to Dutch legislation on privacy and the Dutch 'Code of Conduct for the use of data in health research' [19]. The study did not fall within the scope of the Dutch Medical Research Involving Human Subjects Act and therefore did not require ethical approval.

\section{Data collection}

Year of birth, gender, and postal code area (4-digits) of patients' home address were abstracted from the EMRs of all enlisted patients in the year 2009. For each patient, morbidity data were derived from all consultations and prescriptions recorded in the EMRs. Consultations concerning the same health problem were clustered into episodes of care, defined as all encounters for the management of the same specific health problem, using the computerized algorithm EPICON [20].

Rates were calculated as the total number of episodes of enlisted patients divided by the total number of enlisted patients. One-year prevalence rates were calculated for outcome variables chosen on results from previously published studies: atopic diseases, respiratory and GI infections and 'other infectious disease' which is used for the registration of $\mathrm{Q}$ fever [13]. For several chronic disorders among the selected outcomes, also three-year prevalence rate (2007-2009) were calculated, as some patients with a chronic disorder do not visit a GP yearly and would not be included in the yearly prevalence rates.

Data on the background of the patient (Dutch or foreign) and standardized household income, a proxy for socioeconomic status (SES), in the year 2009 were available from Statistics Netherlands for $84.5 \%$ and $85.2 \%$ of the patients in the high and low exposed populations, respectively.

\section{Exposure assessment}

Numbers and type of CAFOs located in the postal code areas for the year 2009 were obtained from the Dutch Agricultural Geographic Information System GIAB (GIAB 2009, Alterra Wageningen UR, the Netherlands). CAFOs were defined as facilities with $>250$ dairy cows, $>2500$ veal calves, $>7500$ finishing pigs, $>1200$ breeding sows, $>120,000$ laying hens, $>220,000$ broilers, or $>1500$ goats [21]. The number of animals kept in the CAFOs were comparable to the US Environmental Protection Agency (EPA) definition of a medium or large CAFO [22]. Data on CAFOs were only available at the postal code area level, to protect the privacy of the farmers.

\section{Statistical analyses \\ Comparison of prevalence rate between high and low exposed groups}

Multilevel logistic regression analyses with two-level hierarchical structured data (i.e. patients being clustered within general practices) were performed with MLwiN 2.02. [23], adjusting for age (polynomial), gender and registry duration. The centred values of these independent variables (i.e. 40 years of age, $49.3 \%$ males and full year registry duration) were used to obtain comparable estimates for the high and low exposed populations. The potential confounding effect by SES was evaluated by including standardized household income in the models. However, since this did not alter the results, only results without adjustment for SES are shown.

Since prevalence rates of several studied conditions are age-related [13], additional multilevel analyses were performed for specific age groups. Gastroenteritis presumed infection, acute upper respiratory infection, acute laryngitis/tracheitis, asthma and atopic eczema were evaluated among the very young children aged 0 to 4 years. In addition, rates of children aged 0 to 14 years were evaluated for gastroenteritis presumed infection, asthma and atopic eczema. COPD was evaluated for adults aged 45 years or older and for the elderly aged 60 years or more. Results are presented as odds ratios (ORs) with $95 \%$ confidence intervals (CIs).

\section{Semi-individual analyses}

Morbidity data of the year 2009 of the high exposed population were used to study the possible association between prevalence rates of above mentioned conditions and the number of CAFOs located in the proximity (postal code area) of the patients' home. We determined the association with the total number of CAFOs 
(irrespective of the type of animals kept), as well as specific numbers of swine, poultry, cattle and goat CAFOs.

Multilevel logistic regression analysis was used with individual patients (level 1) nested within general practices (level 2). CAFO data were available at the postal code level only. Since patients were classified both by their general practice and by the postal code area of their homes, postal code areas of the patients' home addresses were included in the models as separate level (cross-classified) [24].

We used two different models. The first evaluated the effects of the number of CAFOs located in the same postal code of the patients' home address. However, since people move around in their living environment, the second model evaluated the indirect effects of CAFOs located in the adjacent postal code areas, while ignoring any CAFOs in the residential postal code. Models were performed with MLwiN 2.02. [23], adjusting for age (polynomial), gender, registry duration, the number of inhabitants in the postal code area and total surface area.

\section{Results}

Table 1 shows the descriptives of the high and low CAFO density regions and the characteristics of both populations. In 2009, 129 (30 \%) out of 430 CAFOs registered in the Netherlands were located in the high CAFO density region. The 129 CAFOs were located in
66 of the 171 postal code areas (Fig. 1). Forty-four percent $(n=52,773)$ of the population in this region was living in a postal code area with one of more CAFOs. The mean surface area of these postal codes was $10 \mathrm{~km}^{2}$, ranging from $1.0 \mathrm{~km}^{2}$ to $48.5 \mathrm{~km}^{2}$.

The low CAFO density regions consisted of 785 postal code areas with a total of 10 CAFOs distributed over 7 postal code areas. Three percent $(n=2384)$ of the low exposed population resided in these 7 postal code areas. Mean surface of the low exposed postal code areas was $11.1 \mathrm{~km}^{2}$ (sd 10.6).

Both populations were comparable with respect to standardized household income, place of birth $(>90 \%$ in the Netherlands), and marital status (not in table). The average of the standardized household income of both populations was comparable to that of the Dutch population in the year 2009 (i.e. $€ 23,300$ ) [25].

Table 2 shows one-year prevalence rates of the populations in the high and low CAFO density regions. In general, the prevalence of respiratory and GI diseases in both regions was comparable. Exceptions were 'other infectious disease' (including $\mathrm{Q}$ fever), pneumonia and atopic eczema with an increased prevalence, and sinusitis with a decreased prevalence in the high exposed population.

For several chronic disorders, three-year prevalence rates were estimated (Table 3). Three-year prevalences of the studied chronic disorders were comparable in

Table 1 Characteristics of the high and low CAFO density regions and characteristics of the general practitioners' patients populations, 2009

\begin{tabular}{|c|c|c|}
\hline & High CAFO density region & Low CAFO density regions \\
\hline \multicolumn{3}{|l|}{ Characteristics of the regions } \\
\hline No. of postal code areas & 171 & 785 \\
\hline No. of CAFOs ${ }^{a}$ & 129 & 10 \\
\hline Swine & 85 & 2 \\
\hline Poultry & 28 & 1 \\
\hline Cattle & 10 & 7 \\
\hline Goat & 6 & 0 \\
\hline No. of general practices & 28 & 22 \\
\hline No. of general practitioners & 66 & 32 \\
\hline \multicolumn{3}{|l|}{ Characteristics of the populations } \\
\hline Total No. of patients ${ }^{b}$ & 119,036 & 78,060 \\
\hline Gender (females); n (\%) & $58,952(49.5)$ & $38,983(49.9)$ \\
\hline Age (yrs); mean $\pm S D$ & $40 \pm 23$ & $39 \pm 23$ \\
\hline No. of patients aged 0-14 yrs; n (\%) & $21,509(18.1)$ & $14,805(19.0)$ \\
\hline No. of patients aged $\geq 65 \mathrm{yrs} ; \mathrm{n}$ (\%) & $18,318(15.4)$ & $11,880(15.2)$ \\
\hline Standardized household income $x € 1000^{c}$; mean \pm SD & $24.6 \pm 15.5$ & $24.3 \pm 15.6$ \\
\hline
\end{tabular}

Note. CAFO concentrated animal feeding operation, $S D$ standard deviation

${ }^{a}$ Data from GIAB (GIAB 2009, Alterra Wageningen UR, the Netherlands)

${ }^{\mathrm{b}}$ All enlisted patients in the year 2009

cCalculations made by NIVEL using custom-made microdatasets from Statistics Netherlands concerning NIVEL project 7093 
Table 2 One-year prevalence rates (per 1000 patients) and odds ratios of the general practitioners' patients populations in regions with high and low CAFO density, 2009

\begin{tabular}{|c|c|c|c|}
\hline Diagnosis & High CAFO density region & Low CAFO density regions ${ }^{a}$ & OR $(95 \% \mathrm{Cl})^{\mathrm{b}}$ \\
\hline Other infectious disease & 3.32 & 1.71 & $1.95(1.17-3.26)$ \\
\hline Gastrointestinal infection & 0.81 & 0.75 & $1.08(0.65-1.80)$ \\
\hline Gastroenteritis presumed infection & 4.36 & 4.99 & $0.87(0.62-1.22)$ \\
\hline Age group $0-4$ yrs & 44.72 & 54.22 & $0.82(0.58-1.14)$ \\
\hline Age group 0-14 yrs & 10.77 & 13.16 & $0.82(0.58-1.15)$ \\
\hline Chronic enteritis & 3.29 & 2.47 & $1.33(0.99-1.79)$ \\
\hline Allergic conjunctivitis & 3.64 & 4.59 & $0.79(0.57-1.09)$ \\
\hline Acute URI & 27.59 & 28.41 & $0.97(0.73-1.29)$ \\
\hline Age group 0-4 yrs & 177.77 & 182.63 & $0.97(0.73-1.29)$ \\
\hline Sinusitis acute/chronic & 25.56 & 37.14 & $0.68(0.52-0.88)$ \\
\hline Laryngitis/tracheitis acute & 0.75 & 1.01 & $0.74(0.40-1.39)$ \\
\hline Age group $0-4$ yrs & 11.57 & 16.42 & $0.70(0.43-1.14)$ \\
\hline Influenza & 8.48 & 9.72 & $0.87(0.53-1.42)$ \\
\hline Pneumonia & 5.58 & 3.93 & $1.42(1.12-1.82)$ \\
\hline Asthma & 24.69 & 26.11 & $0.94(0.73-1.22)$ \\
\hline Age group 0-4 yrs & 28.49 & 21.80 & $1.32(0.89-1.95)$ \\
\hline Age group 0-14 yrs & 24.74 & 23.27 & $1.06(0.81-1.41)$ \\
\hline Age group $\geq 65$ yrs & 19.25 & 20.49 & $0.94(0.65-1.36)$ \\
\hline Hay fever & 30.21 & 37.25 & $0.81(0.65-1.00)$ \\
\hline COPD & 3.09 & 3.12 & $0.99(0.78-1.26)$ \\
\hline Age group $\geq 45$ yrs & 27.83 & 28.48 & $0.98(0.77-1.24)$ \\
\hline Age group $\geq 60$ yrs & 51.54 & 53.55 & $0.96(0.75-1.23)$ \\
\hline Atopic eczema & 7.75 & 5.68 & $1.37(1.05-1.79)$ \\
\hline Age group 0-4 yrs & 77.65 & 60.89 & $1.30(1.02-1.65)$ \\
\hline Age group 0-14 yrs & 25.79 & 21.22 & $1.22(0.96-1.55)$ \\
\hline
\end{tabular}

Note. OR odds ratio, $\mathrm{Cl}$ confidence interval, URI upper respiratory infection, COPD chronic obstructive pulmonary disease

${ }^{\mathrm{a}}$ Reference group

${ }^{\mathrm{b}}$ Adjusted for age, gender, and registry duration

Table 3 Three-year prevalence rates (per 1000 patients) and odds ratios of the general practitioners' patients populations in high and low CAFO density regions, 2007-2009

\begin{tabular}{|c|c|c|c|}
\hline Diagnosis & High CAFO density region & Low CAFO density regions $^{a}$ & OR $(95 \% \mathrm{Cl})^{\mathrm{b}}$ \\
\hline Chronic enteritis & 4.72 & 4.35 & $1.09(0.83-1.42)$ \\
\hline Asthma & 44.32 & 56.16 & $0.78(0.58-1.05)$ \\
\hline Age group 0-4 yrs & 60.39 & 49.69 & $1.23(0.83-1.83)$ \\
\hline Age group 0-14 yrs & 49.56 & 54.20 & $0.91(0.69-1.20)$ \\
\hline COPD & 6.40 & 7.84 & $0.82(0.63-1.06)$ \\
\hline Age group $\geq 45$ yrs & 40.66 & 49.72 & $0.81(0.61-1.08)$ \\
\hline Age group $\geq 60$ yrs & 73.63 & 90.91 & $0.79(0.60-1.06)$ \\
\hline Atopic eczema & 16.73 & 13.92 & $1.21(0.93-1.57)$ \\
\hline Age group 0-4 yrs & 233.04 & 190.27 & $1.29(1.08-1.55)$ \\
\hline Age group 0-14 yrs & 63.47 & 56.24 & $1.14(0.93-1.39)$ \\
\hline
\end{tabular}

Note. $O R$ odds ratio, $\mathrm{Cl}$ confidence interval, COPD chronic obstructive pulmonary disease

aeference group

${ }^{\mathrm{b}}$ Adjusted for age, gender, and registry duration 
both populations, with the exception of atopic eczema in children aged 0 to 4 years. Atopic eczema was more likely to occur in the high CAFO density region compared to the low exposed regions, both for the one-year and three-years prevalence.

Data from the high CAFO density region were used to determine the relation between the diagnoses presented in Tables 2 and 3 and the number of CAFOs in the proximity of the patients' homes. Table 4 shows the results for all types of CAFOs, as well as animal-specific CAFOs with the most pronounced associations. In Additional file 1, all results of the analyses are shown.

Goat CAFOs showed the most statistically significant associations (Table 4). Patients with one additional goat CAFO in their residential postal code area were 1.41 times more likely to have pneumonia. In addition, the OR for pneumonia was 1.17 for patients with one additional goat CAFO in any of the adjacent areas. Since the two effects are additive, the odds of pneumonia was increased by $65 \%(1.41 * 1.17)$ for patients living in a postal code area with one goat CAFO and an additional one in the adjacent areas. The presence of one additional goat CAFO inside the postal code area of patients' homes significantly increased the odds of 'other infectious diseases' by $87 \%$, whereas each additional goat CAFO in any of the adjacent areas increased the odds by $77 \%$. In addition, goat CAFOs in adjacent postal code areas were positively associated with allergic conjunctivitis, asthma, hay fever, acute upper respiratory infection and atopic eczema. The presence of one additional goat CAFO within the postal code area of patients' homes was positively associated with atopic eczema. For all types of CAFOs and for swine CAFOs in adjacent areas,positive associations were observed with acute upper

Table 4 Association between the number of CAFOs in postal code areas and health problems within the high CAFO density region, 2009

\begin{tabular}{|c|c|c|c|}
\hline \multirow[b]{2}{*}{ Diagnosis } & \multirow[b]{2}{*}{ Type of CAFO } & \multicolumn{2}{|c|}{ OR $(95 \% \mathrm{CI})^{\mathrm{a}}$ for each additional CAFO } \\
\hline & & Within the postal code area & In adjacent postal code areas \\
\hline \multirow[t]{2}{*}{ Other infectious disease } & All & $0.88(0.75-1.03)$ & $1.00(0.95-1.05)$ \\
\hline & Goat only & $1.87(1.11-3.13)$ & $1.77(1.30-2.41)$ \\
\hline Gastroenteritis presumed infection & All & $0.93(0.86-1.01)$ & $1.01(0.99-1.04)$ \\
\hline \multirow[t]{2}{*}{ Chronic enteritis } & All & $0.99(0.85-1.15)$ & $0.97(0.93-1.01)$ \\
\hline & Poultry only & $1.13(0.79-1.62)$ & $0.89(0.79-1.00)$ \\
\hline \multirow[t]{2}{*}{ Allergic conjunctivitis } & All & $1.00(0.88-1.14)$ & $1.02(0.98-1.06)$ \\
\hline & Goat only & $1.57(0.99-2.50)$ & $1.42(1.10-1.83)$ \\
\hline \multirow[t]{3}{*}{ Acute URI } & All & $1.03(0.96-1.11)$ & $1.03(1.01-1.06)$ \\
\hline & Swine only & $1.10(0.98-1.24)$ & $1.04(1.01-1.08)$ \\
\hline & Goat only & $0.95(0.69-1.29)$ & $1.37(1.12-1.66)$ \\
\hline \multirow[t]{2}{*}{ Pneumonia } & All & $1.03(0.95-1.11)$ & $1.00(0.98-1.03)$ \\
\hline & Goat only & $1.41(1.08-1.84)$ & $1.17(1.00-1.37)$ \\
\hline \multirow[t]{2}{*}{ Asthma } & All & $1.03(0.98-1.08)$ & $1.00(0.98-1.01)$ \\
\hline & Goat only & $1.16(0.94-1.43)$ & $1.15(1.01-1.31)$ \\
\hline Age group 0-4 yrs & All & $0.82(0.66-1.02)$ & $1.02(0.96-1.08)$ \\
\hline Age group 0-4 yrs & Goat only & $0.92(0.45-1.88)$ & $1.62(1.15-2.28)$ \\
\hline Age group 0-14 yrs & All & $0.97(0.87-1.08)$ & $0.99(0.97-1.03)$ \\
\hline Age group 0-14 yrs & Goat only & $1.40(0.96-2.04)$ & $1.37(1.13-1.67)$ \\
\hline \multirow[t]{2}{*}{ Hay fever } & All & $1.01(0.94-1.07)$ & $1.00(0.98-1.02)$ \\
\hline & Goat only & $1.19(0.90-1.56)$ & $1.22(1.05-1.41)$ \\
\hline COPD & All & $1.04(0.97-1.12)$ & $1.00(0.98-1.02)$ \\
\hline Age group 45 yrs and older & All & $1.07(1.01-1.14)$ & $1.00(0.98-1.02)$ \\
\hline Age group 60 yrs and older & All & $1.13(1.02-1.24)$ & $0.98(0.95-1.00)$ \\
\hline \multirow[t]{2}{*}{ Atopic eczema } & All & $1.02(0.97-1.08)$ & $1.01(0.99-1.03)$ \\
\hline & Goat only & $1.26(1.00-1.59)$ & $1.19(1.03-1.38)$ \\
\hline
\end{tabular}

Note. CAFO concentrated animal feeding operations, OR odds ratio, $\mathrm{Cl}$ confidence interval, URI upper respiratory infection. See also Additional file 1 ${ }^{a}$ Adjusted for age, gender, registry duration, the number of inhabitants in the postal code area and total surface area

${ }^{b}$ Defined as $>250$ dairy cows or $>2500$ veal calves (cattle CAFO), $>7500$ finishing pigs or $>1200$ breeding sows (swine CAFO), $>120,000$ laying hens or $>220,000$ broilers (poultry CAFO), or $>1500$ goats (goat CAFO) 
respiratory infections. COPD among adult patients aged 45 years or older was positively associated with number of CAFOs in the postal code area of patients' home. The association was stronger among the age group of 65 years or older.

\section{Discussion}

The prevalence of respiratory and GI conditions in a Dutch rural region with a high CAFO density was comparable to other rural regions with a low CAFO density. Exceptions were pneumonia, atopic eczema and 'other infectious diseases' (among which Q fever) with a significantly higher prevalence. In the high CAFO density region, the number of goat CAFOs was positively associated with pneumonia and 'other infectious diseases'. No relationship between the number of CAFOs and GI conditions was found.

The current study is part of a larger Dutch study in which the health effects of livestock farming among neighbouring residents were investigated during the years 2006 to 2009 [12]. Previously published results used individual-level density of all animal farms, irrespective of their size, within a $5 \mathrm{~km}$ radius around residents' homes using a Geographic Information System $[5,13]$. The present semi-individual study focussed more specifically on the number of CAFOs in or around the postal code area of residents' homes, because potential health effects due to the presence of 'mega farms' are a growing topic of debate in the Netherlands. Despite these differences in design, both studies showed a positive association between goats and pneumonia as well as 'other infectious diseases'( $\mathrm{Q}$ fever).

Between 2007 and 2009, a large Q fever outbreak took place in the high CAFO density region [26]. Q fever is caused by the bacterium Coxiella burnetii and humans become infected through inhalation of contaminated dust and aerosols, released by infected ruminants. The high prevalence of pneumonia found in our study coincided with the $\mathrm{Q}$ fever outbreak. However, additional evaluations of GP morbidity data of the year 2006 showed that the prevalence of pneumonia was 3.4 per 1000 persons in the high CAFO density region versus 2.5 per 1000 in the low CAFO density regions $(\mathrm{OR}=$ $1.37 ; 95 \% \mathrm{CI}=0.89-2.09$ ). Although not statistically different, this difference suggests that pneumonia prevalence rates in the study area were already increased in the year 2006, preceding the $Q$ fever outbreak. In addition to goat CAFOs, the results from our individuallevel study indicated that also smaller goat farms as well as poultry farms were associated with the increase of pneumonia cases in the study area [13].

In pre-school children, atopic eczema was more likely to occur in the proximity of goat CAFOs. It is unclear which farm exposures could be responsible for this finding. In contrast, numerous studies reported a reduced risk of allergic conditions such as atopic eczema, allergic rhinitis and allergic asthma among children who grew up on farms (reviewed in [27, 28]). In our previous individual-level study, we also found inverse associations between farm exposures and asthma and allergic rhinitis both in children (0-17 years) and adults [5].

COPD was more likely to occur in the close proximity of CAFOs. This is in contrary to our previous individual-level study, in which we found an inverse association between farm exposures and COPD [5]. This inverse association was counterintuitive, since it is not biologically plausible that farm-related exposure may protect against COPD. In addition, previous research showed that livestock farmers are at increased risk of developing COPD due to high levels of endotoxin and other microbial components in stable dust [29].

The present evidence on effects of CAFOs on respiratory, atopic or GI conditions is mostly limited to swine CAFOs [3, 6, 30-32]. We were able to study the separate effects of swine, cattle, poultry, and goat CAFOs. In contrast to the earlier studies, we observed only weak associations between swine CAFOs and health in neighbouring residents. However, results are difficult to compare, because none of the cited studies used information obtained from EMRs registered by GPs. Furthermore, most researchers used the traditional individual-level study design $[3,6,27]$, while the current study can be considered as a semi-individual study [33]. Likewise to our study, Mirabelli et al. used a multilevel approach to study respiratory outcomes in public schools with children aged 12 to 14 years [31]. An increased risk of self-reported physician-diagnosed asthma was found in children with self-reported allergies who attended schools located within 3 miles distance of a swine CAFO, but there was no clear dose-response relationship.

In contrast to two ecological studies using hospital data $[9,10]$, we did not find a clear association between CAFOs and GI illness. In our study the prevalence of GI infections may be underestimated, because only people with severe illness will consult their GP. A communitybased study using questionnaire data also captured less severe cases of GI illness [34]. Interestingly, they found intensive farming activities to be negatively associated with GI illness.

Our study has several strengths. Outcome variables were obtained from EMRs registered by GPs, which rules out the possibility of recall bias. In the Netherlands, the patient population of a GP can be used as the denominator in epidemiological studies. Exposure data were not self-reported; detailed CAFO data were available at the postal code level. We used multilevel cross-classified models to take into account 
that patients were classified both by their general practice and by their postal code area [24]. In contrast to individual-level and ecological studies, multilevel studies are able to simultaneously examine the role of individual- and group-level factors in the risk of disease [35]. Finally, compared to other studies we were able to use a study design with a control group, by analysing data from persons living in rural areas with few CAFOs.

Several factors may have influenced the internal validity of our study findings. First, we performed a cross-sectional analysis. Consequently, selection bias might have occurred. It is possible that subjects with incipient health problems possibly related to CAFOs have moved from the high exposed region before they could be included in our study. This would lead to an underestimation of effect estimates. Second, only limited information about possible confounders was available in the EMRs. We could adjust for registry duration, age, gender and SES, and at the postal code area level, additional adjustments were made for the number of inhabitants and total surface area, but we were unable to adjust for air pollution caused by industries or traffic. However, by excluding the urban areas (more than 1500 addresses per $\mathrm{km}^{2}$ ) we have reduced the influence of these other sources of air pollution.

\section{Conclusions}

In conclusion, using GP medical records, we found positive associations between the number of goat CAFOs near residents' homes and pneumonia as well as 'other infectious disease'. No association was found between the number of CAFOs and GI conditions. Living nearby cattle, poultry or swine CAFOs was not related to a higher odds of respiratory or GI conditions.

\section{Ethical approval}

The study was carried out according to Dutch legislation on privacy and the Dutch 'Code of Conduct for the use of data in health research'. The study did not fall within the scope of the Dutch Medical Research Involving Human Subjects Act and therefore did not require ethical approval.

\section{Additional file}

Additional file 1: Detailed results of association between the number of CAFOs in the high CAFO density region, 2009. (DOCX $31 \mathrm{~kb})$

\section{Abbreviations}

CAFO: concentrated animal feeding operation; GP: general practitioner; EMR: electronic medical record; ICPC: international classification of primary care.

\section{Competing interests}

The authors declare that they have no competing interests.

\section{Authors' contributions}

FvdS-dB, MH, LAMS, IMW, PS, DJJH and CJY were involved in the conception, hypothesis delineation, and design of the study, and participated in the interpretation of the data. FvdS-dB, MH, and CJY recruited general practitioners and collected the medical data. FvdS-dB and PS conducted the statistical analysis. FvdS-dB drafted the manuscript. All authors reviewed and commented on the manuscript, and approved the final version of the manuscript.

\section{Acknowledgments}

We thank the participating general practitioners for their contribution to this study, Stefan Visscher (NIVEL) for coordinating the data collection, Petra ten Veen (NIVEL) for data management, and Raymond Kenens (NIVEL) for drawing the figure. We are grateful to dr. Edo Gies (Alterra, Wageningen University, the Netherlands) for providing data from the GIAB database.

\section{Source of funding}

Funding for this study was provided by the Dutch Ministry of Economic Affairs, Agriculture and Innovation, and the Dutch Ministry of Health, Welfare and Sport.

\section{Author details}

${ }^{1}$ NIVEL, Netherlands institute for health services research, P.O. Box 15683500BN Utrecht, The Netherlands. ${ }^{2}$ Institute for Risk Assessment Sciences, Division Environmental Epidemiology, Utrecht University, Utrecht, The Netherlands.

Received: 18 June 2015 Accepted: 15 February 2016

Published online: 17 February 2016

\section{References}

1. Radon K, Schulze A, Ehrenstein V, van Strien RT, Praml G, Nowak D. Environmental exposure to confined animal feeding operations and respiratory health of neighboring residents. Epidemiology. 2007;18:300-8.

2. O'Connor AM, Auvermann B, Bickett-Weddle D, Kirkhorn S, Sargeant JM, Ramirez A, et al. The association between proximity to animal feeding operations and community health: a systematic review. PLoS One. 2010;5: e9530. doi:10.1371/journal.pone.0009530.

3. Villeneuve PJ, Ali A, Challacombe L, Hebert S. Intensive hog farming operations and self-reported health among nearby rural residents in Ottawa, Canada. BMC Public Health. 2009;9:330.

4. Schulze A, Rommelt $H$, Ehrenstein V, van Strien R, Praml G, Küchenhoff H, et al. Effects on pulmonary health of neighboring residents of concentrated animal feeding operations: exposure assessed using optimized estimation technique. Arch Environ Occup Health. 2011;66:146-54.

5. Smit LAM, Hooiveld M, van der Sman-de Beer F, Opstal-van Winden AW, Beekhuizen J, Wouters IM, et al. Air pollution from livestock farms, and asthma, allergic rhinitis and COPD among neighbouring residents. Occup Environ Med. 2014;71:134-40.

6. Schinasi L, Horton RA, Guidry VT, Wing S, Marshall SW, Morland KB. Air pollution, lung function, and physical symptoms in communities near concentrated swine feeding operations. Epidemiology. 2011;22:208-15.

7. Pavilonis BT, Sanderson WT, Merchant JA. Relative exposure to swine animal feeding operations and childhood asthma prevalence in an agricultural cohort. Environ Res. 2013;122:74-80.

8. Mohangoo AD, van der Linden MW, Schellevis FG, Raat H. Prevalence estimates of asthma or COPD from a health interview survey and from general practitioner registration: what's the difference? Eur J Public Health. 2006;16:101-5.

9. Haus-Cheymol R, Espie E, Che D, Vaillant V, DE Valk H, Desenclos JC. Association between indicators of cattle density and incidence of paediatric haemolytic-uraemic syndrome (HUS) in children under 15 years of age in France between 1996 and 2001: an ecological study. Epidemiol Infect. 2006;134:712-8

10. Febriani $Y$, Levallois $P$, Lebel $G$, Gingras $S$. Association between indicators of livestock farming intensity and hospitalization rate for acute gastroenteritis. Epidemiol Infect. 2009;137:1073-85.

11. van Os J, Gies TJA. Grootschalige veehouderij in Nederland. Aantal bedrijven, locaties en milieuvergunningen. Wageningen: Alterra; 2011. 
12. Heederik DJJ, Yzermans CJ. Potential Effects of Intensive Livestock Farming on Neighboring Residents' Health. Utrecht: IRAS/NIVEL; 2011.

13. Smit LAM, van der Sman-de Beer F, Opstal-van Winden AWJ, Hooiveld M, Beekhuizen J, Wouters IM, et al. Q fever and pneumonia in an area with a high livestock density: a large population-based study. PLoS One. 2012;7: e38843. doi:10.1371/journal.pone.0038843.

14. Schimmer B, ter Schegget R, Wegdam M, Züchner L, de Bruin A, Schneeberger PM, et al. The use of a geographic information system to identify a dairy goat farm as the most likely source of an urban Q-fever outbreak. BMC Infect Dis. 2010;10:69.

15. Williams DL, Breysse PN, McCormack MC, Diette GB, McKenzie S, Geyh AS. Airborne cow allergen, ammonia and particulate matter at homes vary with distance to industrial scale dairy operations: an exposure assessment. Environ Health. 2011;10:72.

16. Dutch College of General Practitioners. Guideline Accurately recording medical information in electronic medical records. 2014. https://www.nhg. org/themas/artikelen/richtlijn-adequate-dossiervorming-met-het-epd. Accessed 5 Jun 2014.

17. Lamberts $\mathrm{H}$, Wood M. International classification of primary care. Oxford: Oxford University Press; 1987.

18. NIVEL. Netherlands Information Network of General Practice (LINH). 2014. http://www.nivel.nl/en/netherlands-information-network-generalpractice-linh. Accessed 27 Oct 2014

19. Dutch Council of the Federation of Medical Scientific Societies. The Code of Conduct for the use of data in health research. 2014. https://www.federa. org/codes-conduct. Accessed 17 Feb 2016.

20. Biermans MC, de Bakker DH, Verheij RA, Gravestein JV, van der Linden MW, Robbé PF. Development of a case-based system for grouping diagnoses in general practice. Int J Med Inform. 2008;77:431-9.

21. Gies E, van Os J, Hermans T, Olde Loohuis R. Megastallen in beeld. Wageningen: Alterra; 2007.

22. US Environmental Protection Agency. Regulatory Definitions of Large CAFOs, Medium CAFO, and Small CAFOs. 2014. http://www.epa.gov/npdes/ pubs/sector_table.pdf. Accessed 27 Oct 2014.

23. Rasbash J, Charlton C, Browne WJ, Healy M, Cameron B. MLwiN Version 2. 02. Bristol: Centre for Multilevel Modelling, University of Bristol; 2005.

24. Goldstein H. Cross-classified data structures. In: Goldstein H, editor. Multilevel Statistical Models. Chichester, United Kingdom: John Wiley \& Sons Ltd; 2011. p. 243-54.

25. Statistics Netherlands. Average income; Characteristics of private households. 2014. http://statline.cbs.nl. Accessed 27 Oct 2014.

26. Dijkstra F, van der Hoek W, Wijers N, Schimmer B, Rietveld A, Wijkmans CJ, et al. The 2007-2010 Q fever epidemic in The Netherlands: characteristics of notified acute $\mathrm{Q}$ fever patients and the association with dairy goat farming. FEMS Immunol Med Microbiol. 2012;64:3-12.

27. Genuneit J. Exposure to farming environments in childhood and asthma and wheeze in rural populations: a systematic review with meta-analysis. Pediatr Allergy Immunol. 2012;23:509-18.

28. Von Mutius E. Maternal farm exposure/ingestion of unpasteurized cow's milk and allergic disease. Curr Opin Gastroenterol. 2012;28:570-6.

29. Eduard W, Pearce N, Douwes J. Chronic bronchitis, COPD, and lung function in farmers: the role of biological agents. Chest. 2009;136:716-25.

30. Avery RC, Wing S, Marshall SW, Schiffman SS. Odor from industrial hog farming operations and mucosal immune function in neighbors. Arch Environ Health. 2004;59:101-8.

31. Mirabelli MC, Wing S, Marshall SW, Wilcosky TC. Asthma symptoms among adolescents who attend public schools that are located near confined swine feeding operations. Pediatrics. 2006;118:e66-75.

32. Sigurdarson ST, Kline JN. School proximity to concentrated animal feeding operations and prevalence of asthma in students. Chest. 2006;129:1486-91.

33. Kunzli N, Tager IB. The semi-individual study in air pollution epidemiology: a valid design as compared to ecologic studies. Environ Health Perspect. 1997;105:1078-83.

34. Febriani Y, Levallois $P$, Gingras $S$, Gosselin P, Majowicz SE, Fleury MD. The association between farming activities, precipitation, and the risk of acute gastrointestinal illness in rural municipalities of Quebec, Canada: a crosssectional study. BMC Public Health. 2010;10:48.

35. Diez-Roux AV. The study of group-level factors in epidemiology: rethinking variables, study designs, and analytical approaches. Epidemiol Rev. 2004;26:104-11.

\section{Submit your next manuscript to BioMed Central and we will help you at every step:}

- We accept pre-submission inquiries

- Our selector tool helps you to find the most relevant journal

- We provide round the clock customer support

- Convenient online submission

- Thorough peer review

- Inclusion in PubMed and all major indexing services

- Maximum visibility for your research

Submit your manuscript at www.biomedcentral.com/submit
Biomed Central 